\title{
The Representation of Bilingual Mental Lexicon and English Vocabulary Acquisition
}

\author{
Zhang Ying ${ }^{1}$ \\ ${ }^{1}$ English Department, North China Electric Power University, Baoding, Hebei Province, China \\ Correspondence: Zhang Ying, English Department, North China Electric Power University, Baoding, Hebei \\ Province, China. E-mail: zhang_ying2004@163.com
}

Received: September 6, 2017

Accepted: October 30, 2017 Online Published: November 1, 2017

doi: $10.5539 /$ elt.v10n12p24

URL: http://doi.org/10.5539/elt.v10n12p24

\begin{abstract}
This paper provides an overview of the theories on the organization and development of L1 mental lexicon and the representation mode of bilingual mental lexicon. It analyzes the structure and characteristics of Chinese EFL learners and their problems in English vocabulary acquisition. On the basis of this, it suggests that English vocabulary teaching should be adjusted to learners' various proficiency levels at different stages. Learners should pay attention to the mediating role of Chinese, cultivate their English thinking pattern, and strengthen the development of in-depth vocabulary knowledge.
\end{abstract}

Keywords: mental lexicon, representation, interference of L1, second language acquisition

\section{Introduction}

The mental lexicon is defined as a mental representation of words stored in memory, including information about a word's meaning, pronunciation, syntactic characteristics, and so on (Carroll, 1999) Mental lexicon theory mainly studies the construction and characteristics of the psychological representation of words and their meanings. It consists of three main parts: vocabulary knowledge, the organization of mental lexicon, and vocabulary extraction. Vocabulary knowledge includes phonetics, syntax, morphology and semantics. The organization of mental lexicon means how vocabulary knowledge is stored in memory. Vocabulary extraction is the process of activation of lexical knowledge. There are numerous words stored in the mental lexicon. In human brains, words are stored in a certain order rather than being placed at random. Then, how the mental lexicon is being organized in human brains? How to organize and represent the mental lexicon of bilingual users? By understanding and mastering these rules, what are the implications for Chinese EFL learners in vocabulary teaching and learning?

\section{The Organization and Development of L1 Mental Lexicon}

\subsection{The Organization of L1 Mental Lexicon}

Presently, there are basically two assumptions concerning the organization structure of L1 mental lexicon: hierarchical network models and spreading activation model. Both of them are based on the concept of lexical semantic network, which refers to the organization of mutually connected words and words meanings in mental lexicon (Wang, 2002). Hence, the organization structure of L1 mental lexicon is considered to be composed mainly of the connections among words meanings.

Collins and Quillian (1970) put forward the hierarchical network model. It is believed that some concepts, such as "animal" and "fish", are all represented as nodes and stored at the same level in human's brain.These nodes are linked by a network representing the relationship between different concepts, and these nodes of concepts are hierarchical in the network. For example, the node representing "animal" is higher than that of "fish". This model shows words' categories and attributes. That is, words are classified and stored in different categories in memory.However, the major problem with the hierarchical network model lies in that by using this model, we fail to explain the reason why the extraction speeds of words at the same level are different.

Spreading activation model, however, tries to reveal the organization structure of words and words' meanings in human brains from another perspective. The organization of words are not strictly hierarchical. On the contrary, it is more likely to be a network constituted by interrelated nodes, and the distances between different nodes are decided by the structure features and elements of connected concepts. Spreading activation model preserves the 
idea in the hierarchical network model that concepts are interrelated, and at the same time it discards the idea that all the connections are of equal status. Besides, this model puts forward that some nodes are easier to extract than others because of their high use frequency and typical effects. According to this model, in the process of activation and diffusion of words, activation starts from one certain node and then spreads to the whole network to activate other nodes associated with this.

\subsection{Acquisition and Development of L1 Vocabulary}

The development of L1 mental lexicon is a dynamic process. To be specific, the reformation of L1 mental lexicon takes place during the process of new words' addition and old words' disappearance. In the process of vocabulary acquisition, children are facing three main tasks: labeling, packing and constructing networks. Labeling is the fact that children have to find out a string of words to refer to a particular object in life. Packing means that children must realize that some objects can be packed stored in the same labeled category. Constructing networks means that they must be able to find out how words are connected with each other.

Harris (1992) believes that the development of L1 vocabulary must undergo three stages. The first stage is a tough and slow process that starts from an infants' responses to what he heard and ends up with being able to speak out as many as 30 words. The second stage, usually lasting for several years, is also called vocabulary boom period because vocabulary is enlarged and extended rapidly at this stage. The third stage is the period of reorganization of the words knowledge when children continue to review, reconstruct and consolidate the knowledge of vocabulary. The reorganization of vocabulary is carried out from two aspects: one is to classify the words into different categories according to their interconnection; the other is to further complicate the connection between words and concepts.

Obviously, Aitchison's (1987) three tasks children facing in L1 vocabulary development are essentially the same with the three stages put forward by Harris (1992). That is, the L1 mental lexicon has come through the process from building to developing and to reconstructing. While the acquisition of L2 vocabulary is developed on the basis of the learner's L1 semantic network, then how the mental lexicon is organized and represented in the bilingual users' brain?

\section{Organizational Structure and Representation of Bilingual Mental Lexicon}

In the early studies abroad, the bilingual mental lexicon was divided into three categories according to different organizational ways: coordinate, compound, subordinate (Weinreich, 1953). On the basis of this, later researchers further divided the representation of bilingual mental lexicon into seven models through experimental methods: independent storage model, word association, concept mediation, mixed model, asymmetric model, distributed model, dual-coding model (Dong \& Gui, 2002). Among these models, the model of word association and concept mediation are more controversial. On this issue, Levelt (1989) gives another interpretation (Figure 1). He believes that the internal structure of the lexical entry includes lemma and lexeme two parts. Lemma contains semantics and syntax, such as word meaning, word-class knowledge, while lexeme contains morphology and phonology, such as different variations of words, and ways of spelling.

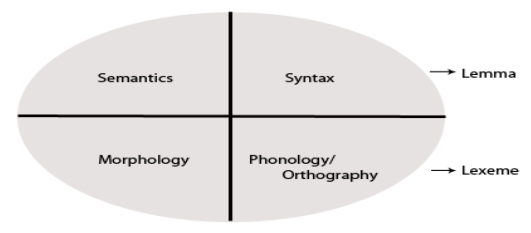

Figure 1. Levelt's (1989) internal structure of the lexical entry

For Chinese EFL learners, the L2 is acquired under the environment of their home country after the acquisition of the L1, so that they should be labeled as coordinate bilinguals. The organization of their bilingual mental lexicon also has unique characteristics. Dong (1988) found that given the characteristics of Chinese EFL learners' mental lexicon, word association model and concept mediation model are not opposite to each other, but are related to learners' proficiency levels. For less proficient learners, it's likely that the bilingual representation is realized by associating with the Chinese equivalents. But with the improvement of learners' language proficiency, this representation is realized more through concept mediation model. On the basis of 
Levelt's (1989) model, Jiang (2000) divided representation of the L2 vocabulary acquisition into three stages: form stage, L1 lemma mediated stage, and L2 integrated stage. Chen Shufang (2004) employed this model to explain the phenomenon of Chinese EFL learners' vocabulary fossilization in learning English. In her view, the second stage is of critical importance in the whole process of English vocabulary acquisition. Because the connection between linguistic forms and conceptual representation is weak at this stage, and at the same time, the space of L2 lexicon in mind is occupied by a large number of Chinese equivalents through translation, which leads to the slow development of learners' L2 vocabulary and the phenomenon of fossilization.

\section{Implications for English Vocabulary Teaching}

\subsection{Attaching Importance to the Differences between Native Language and Target Language in Semantics}

Because of the differences in cultural background, living environment, and social factors, the semantic meanings of vocabulary in English and in Chinese are corresponding, but not equivalent. According to the differences of the corresponding relationship, it can be divided into three kinds of situations: complete correspondence, partial correspondence and no correspondence. For the study of vocabulary in the latter two situations, learners should understand and build up the network of the specific meanings of words according to the concrete context. In teaching English vocabulary, teachers should consciously create contexts to lead students to input new words through sentences or texts.

\subsection{Paying Attention to the Role of Interlanguage at Different Stages of EFL Learning and Cultivating Learners' Pattern of English Thinking}

It is not proper to attribute all the problems encountered by Chinese EFL learners to the interference or the effect of negative transfer of Chinese in the process of vocabulary acquisition, which should be analyzed based on learners' proficiency levels. The L2 is developed on the basis of the L1, and learners can not completely avoid the influence exerted by their L1 in the L2 learning process. In this case, then how to handle the role of the L1 in the process of L2 acquisition? On the one hand, there are some semantically identical words in English and in Chinese. At the early stage of English learning, because of the limited number of English words that learners have mastered, it is impossible to explain the new words in English, and then it's surely an effective way to introduce and explain the words' meanings by translating into Chinese to enlarge learners' English vocabulary rapidly. However, on the other hand, this method also has many drawbacks. First, because of the intervention of L1, it reduces the learner's direct contact with the L2. Second, the overuse of the L1 also hinders the process of the integration of the L2 vocabulary in learners' mental lexicon, because the connection between learners' L2 vocabulary and their mother tongue is a barrier to the establishment of networks between L2 words. Without enough connections between the L2 vocabulary, the process of lexical access is slow and unreliable. Therefore, for intermediate English learners, if they continue to depend on translation and Chinese equivalents to enlarge their vocabulary, it will exert a negative effect on the development of the L2 vocabulary because of the interference of L1. Intermediate English learners should pay attention to avoid the interference of their L1, and strive to build up direct relationship between linguistic forms and semantic meanings of the L2 to cultivate the pattern of English thinking in a relatively authentic English learning environment.

\subsection{Attaching Importance to the Development of in-Depth Vocabulary Knowledge}

Teachers should cultivate learners' consciousness of further development of in-depth knowledge of words that have been learned, especially at the intermediate and advanced level, to prevent the phenomenon of fossilization. For example, teachers should guide students to classify the existing words in the mental lexicon into different categories and to put new words in the corresponding category to build up its connection with other words in the same category, such as summing up all the words that belong to the same semantic field. Only when the connections between the new information and the old one are established can it be deeply carved into our mind and be kept in memory for long. Also, this helps learners improve their efficiency of vocabulary access. The more, the stronger the connections, the easier it is to activate related words and explore the depth of vocabulary knowledge.

\section{Conclusions}

It is of great significance for Chinese EFL teachers and learners to strengthen studies on mental lexicon, understand the constructional differences between the L1 and the L2 mental lexicon and know about the unique characteristics of Chinese EFL learners' bilingual mental lexicon and their English vocabulary acquisition process. It is of great help to guide language learners to build up a mental lexicon effectively and reasonably and to improve their skills of listening, speaking, reading and writing in learning English. 


\section{Acknowledgments}

This research was financially supported by "the Fundamental Research Funds for the Central Universities+2015MS68".

\section{References}

Aitchison, J. (1987). Words in the minds: An introduction to mental lexicon. Oxford: BasilBlackwell.

Bernstein, T. M. (1995). The careful writer: A modern guide to English usage (2nd ed.). New York, NY: Atheneum.

Carrol, D. (1999). Psychology of language. New York: Brooks/Cole Publishing Company.

Chen, S. F. (2004). An analysis of the Fossilized Phenomenon in the Development of L2 mental lexicon. Journal of Xiangtan University, 3, 156-159.

De Groot, A. M. B., \& Hoeks, J. C. J. (1995). The development of bilingual memory: evidence for asymmetric connections between bilingual memory representations. Journal of Memory and Language, 33, 149-174.

Dong, Y. P. (1998). The conceptual Organization of the Bilingual Mental Lexicon: The shared (distributed) asymmetrical model. Guangzhou: Guangdong University of Foreign Studies Press.

Dong, Y. P., \& Gui, S. C. (2002) On the Representational Structure of the Bilingual Mental Lexicon. Journal of Foreign Language, 4, 23-29.

Garman, M. (1990). Psycholinguistics. Cambridge: CUP. https://doi.org/10.1017/CBO9781139165914

Harris, M. (1992). Language experience and early language development: From input to output. Hove \& Hillsdale, NJ: Lawrence Eelbaum.

Jiang, N. (2000). Lexical representation and development in a second language. Applied Linguistics, 21(1), 47-77. https://doi.org/10.1093/applin/21.1.47

Li, R. B., \& Peng, R. L. (1999). Sementic representation of bilingual learners. Modern Foreign Languages, 3 , 255-272.

Wang, W. B. (2002). Psychological Research on Words and their Meanings A Survey of the Mental Lexicon Theory. Modern Foreign Languages, 4, 423-433.

\section{Copyrights}

Copyright for this article is retained by the author(s), with first publication rights granted to the journal.

This is an open-access article distributed under the terms and conditions of the Creative Commons Attribution license (http://creativecommons.org/licenses/by/4.0/). 